\title{
T-Cell Surface Glycoprotein CD1c
}

National Cancer Institute

\section{Source}

National Cancer Institute. T-Cell Surface Glycoprotein CD1C. NCI Thesaurus. Code

C118909.

T-cell surface glycoprotein CD1c (333 aa, 38 kDa) is encoded by the human CD1C gene.

This protein is involved in lipid and glycolipid antigen presentation to T-cells. 